\title{
Editorial
}

\section{Is CA 19-9 of Any Help in the Management of Cholangiocarcinoma?}

\author{
Marília Cravo \\ Gastroenterology Department, Hospital Beatriz Ângelo, Loures, Portugal
}

Keywords

CA 19-9 · Cholangiocarcinoma · Prognosis

\section{O Valor de CA 19-9 Pode Ser Útil no Manejo do Colangiocarcinoma?}

Palavras Chave

CA 19-9 · Colangiocarcinoma · Prognóstico

Cholangiocarcinoma is a malignant neoplasm with a poor prognosis that is generally diagnosed at an advanced stage. Surgery remains the only option for curative therapy, although preoperative resectability evaluation remains a challenge in these patients [1]. Computed tomography and magnetic resonance cholangiopancreatography are usually used, alone or in combination, to decide which therapeutic approach is the best. Nevertheless, preoperative evaluation is sometimes difficult. Some tumors are considered resectable in view of preoperative imaging, but the intraoperative findings of biliary involvement and vascular invasion often do not match with the preoperative assessment. For these reasons, there is an urgent need to improve the preoperative evaluation of these patients $[2,3]$.

\begin{tabular}{|c|c|}
\hline & (C) 2017 Sociedade Portuguesa de Gastrenterologia \\
\hline 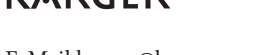 & Published by S. Karger AG, Basel $\quad$ Karger \\
\hline www.karger.com/pjg & $\begin{array}{l}\text { This article is licensed under the Creative Commons Attribution- } \\
\text { NonCommercial-NoDerivatives } 4.0 \text { International License (CC BY- } \\
\text { NC-ND) (http://www.karger.com/Services/OpenAccessLicense). } \\
\text { Usage and distribution for commercial purposes as well as any dis- } \\
\text { tribution of modified material requires written permission. }\end{array}$ \\
\hline
\end{tabular}

Previous studies indicated that serum tumor markers such as CA 19-9 are important in the diagnosis and prognosis of these tumors [4]. CA 19-9 is routinely measured for diagnostic purposes, in the differential diagnosis of other biliary or liver changes/masses as well as after curative surgery to detect relapse of disease $[5,6]$. The serum CA 19-9 level depends on the Lewis phenotype, and about $5-14 \%$ of the population is Lewis negative (Lea-b-), which is characterized by the CA 19-9 non-secretory phenotype. Lewis-negative (Lea-b-) patients cannot secrete CA 19-9 even when they have a malignant tumor, which is associated with poor survival outcomes despite curative resection. When using CA 19-9 as a diagnostic and/or prognostic marker, we also have to consider the impact of obstructive jaundice on the serum CA 19-9 levels. Very high levels of total bilirubin artificially elevate CA 19-9, which may interfere with or even impair its diagnostic accuracy. Besides diagnosis, this serum tumor marker has been used to predict the resectability of gastrointestinal malignancies [7]. In a recently published study, $\mathrm{Hu}$ et al. [8] evaluated the value of the preoperative serum CA 19-9 level in predicting the resectability of hilar cholangiocarcinoma. The authors observed that in patients with potentially resectable tumors judged by radiologic examination and with normal bilirubin levels, ROC curve analysis calculated an ideal CA 19-9 cutoff value of $203.96 \mathrm{U} / \mathrm{mL}$ in the prediction of resectability, with a sensitivity of $83.7 \%$, specificity of $80 \%$, positive predictive value of

Dr. Marília Cravo

Gastroenterology Department, Hospital Beatriz Ângelo

Avenida Carlos Teixeira, 3

PT-2674-514 Loures (Portugal)

E-Mail marilia.cravo@sapo.pt 
$91.1 \%$, and a negative predictive value of $66.7 \%$. Obviously, tumor biomarkers should act as complementary instrument to the preoperative imaging evaluation, and a comprehensive combination of clinical manifestation, preoperative imaging, and other prognostic factors including the tumor size and location are used to decide the best therapeutic approach.

In this issue of GE, Coelho et al. [9] published a retrospective observational study of 89 patients with a diagnosis of cholangiocarcinoma in whom the authors aimed at determining (i) the association between serum CA 19-9 and clinical and laboratory changes, and (ii) its association with survival. The authors noted that the median value for CA 19-9 was $103.0 \mathrm{U} / \mathrm{mL}$ with no differences observed according to the type of cholangiocarcinoma. Patients with values above $103.0 \mathrm{U} / \mathrm{mL}$ had higher values of alkaline phosphatase and gamma-glutamyltransferase but significantly lower values of albumin. More interest- ingly, CA 19-9 values above that threshold were associated with a lower overall survival $(p=0.01)$ as well as with treatment with a curative intent - surgery versus palliative chemotherapy. The latter indirectly reflects preoperative irresectability as in the study by $\mathrm{Hu}$ et al. [8]. Finally, in a multivariate analysis, CA 19-9 serum levels lower than $103 \mathrm{U} / \mathrm{L}$ and surgery were independent predictors of survival. It is not clear whether there was any interference between CA 19-9 and bilirubin levels in the study by $\mathrm{Hu}$ et al. [8].

All together, these data indicate that measuring CA 19-9 in patients with cholangiocarcinoma might be useful (i) in the diagnostic workup, (ii) as a prognostic factor, and (iii) as an indicator of tumor resectability. The threshold value is rather low (below $200 \mathrm{U} / \mathrm{L}$ ), although it varies between the published studies. When planning to operate on a patient with cholangiocarcinoma, the CA 19-9 value should definitely be taken into account.

\section{References}

1 Saxena A, Chua TC, Chu FC, Morris DL: Improved outcomes after aggressive surgical resection of hilar cholangiocarcinoma: a critical analysis of recurrence and survival. Am J Surg 2011;202:310-320.

2 Jarnagin WR, Fong Y, DeMatteo RP, Gonen M, Burke EC, Bodniewicz BJ, Youssef BM, Klimstra D, Blumgart LH: Staging, resectability, and outcome in 225 patients with hilar cholangiocarcinoma. Ann Surg 2001;234: 507-517.

3 Ebataa T, Ercolanib G, Alvaroc D, Riberod D, Tommasoe LD, Vallef JW: Current status on cholangiocarcinoma and gallbladder Cancer. Liver Cancer 2017;6:59-65.
4 Liang B, Zhong L, Qun He, Wang S, Pan Z, Wang T, Zhao T: Diagnostic accuracy of serum CA19-9 in patients with cholangiocarcinoma: a systematic review and meta-analysis. Med Sci Monit 2015;21:3555-3563.

5 Juntermanns B, Radunz S, Heuer M, Hertel S, Reis H, Neuhaus JP, Vernadakis S, Trarbach T, Paul A, Kaiser GM: Tumor markers as a diagnostic key for hilar cholangiocarcinoma. Eur J Med Res 2010;15:357-336.

6 Wang Y-Y, Zhong J-H, Lu Z, Qin H-G, Li L-Q: Does the elevation of serum carbohydrate antigen 19-9 level predict poor overall survival in patients with hepatocellular carcinoma? Tumor Biol 2015;36:8273-8274.
7 Brown EG, Canter RJ, Bold RJ: Preoperative CA 19-9 kinetics as a prognostic variable in radiographically resectable pancreatic adenocarcinoma. J Surg Oncol 2015;111:293-299.

$8 \mathrm{Hu}$ HJ, Mao H, Tan YQ, Shrestha A, Ma WJ, Yang Q, Wang JK, Cheng NS, Li FY: Clinical value of preoperative serum CA 19-9 and CA 125 levels in predicting the resectability of hilar cholangiocarcinoma. Springerplus 2016;5: 551.

9 Coelho R, Silva M, Rodrigues-Pinto E, Cardoso H, Lopes S, Pereira P, Vilas-Boas F, Santos-Antunes J, Costa-Maia J, Macedo G: CA 19-9 as a marker of survival and a predictor of metastization in cholangiocarcinoma. GE Port J Gastroenterol 2017, DOI: 10.1159/ 000452691.
Is CA 19-9 of Any Help in the

Management of Cholangiocarcinoma?
GE Port J Gastroenterol 2017;24:108-109 DOI: $10.1159 / 000457910$ 